\title{
Localisation of the chronic osteoarthropathy related to dysbarism
}

\author{
I RÓZSAHEGYI \\ From Semmelweis Medical University, Budapest, Hungary
}

There is still no general consensus on the aetiology of the osteonecrosis related to dysbarism. Various theories have been developed about the pathological mechanisms but all are, in some way, related to the supersaturation of tissues with gas. Changes in the structure of bone occur fairly commonly in compressed air workers and divers, but most lesions do not give rise to symptoms or clinical signs other than radiological changes. ${ }^{1}$

Almost exclusively, symptoms are associated only with those lesions affecting the shoulder and the hip joint. No explanation for this fact can be found in the many reports on dysbaric osteonecrosis. Weight bearing alone is obviously not the explanation since the knee and ankle joints are never affected by the disease despite the fact that they bear the same load as the hip. Lesions at the lower end of the femur are typically symptomless and non-disabling. ${ }^{1}$

In what respects do the shoulder and hip joints differ from the other joints of the body?

(1) In adults the only long bones in which haematopoietic (red) marrow can be found are the proximal epiphysis of the femur and humerus.

(2) Two thirds of the fatty (yellow) marrow of the adult human are in the diaphysis of the femur and humerus.

Fat can absorb more than five times as much nitrogen as water so that it is possible that large quantities of nitrogen may be present in the diaphysis of the femur and the humerus, if the period spent under increased pressure is long enough to saturate the fat ("slow tissue") or if the intervals between succeeding exposures to compressed air are too short to eliminate the whole of the absorbed quantity of nitrogen. That remaining from the preceding exposures would lead to an increasing quantity of gas being left in the diaphysal cavity, even if the duration of each single exposure was not sufficient to saturate the fat with nitrogen. Such a build up of gas in solution could explain the high incidence of bone lesions in Mil-

Accepted 4 November 1985 waukee caisson workers when working split shifts reported by Kindwall ${ }^{2}$ and the absence of aseptic bone necrosis after 1963 when they began to use the Washington State decompression tables which did not al- $\infty$ low split shifts.

Supersaturation in the bone marrow may produce damage to bone at gas tension levels below those which cause symptoms of dysbarism elsewhere in the body. ${ }^{3}$

There is nothing to prevent the flow of free gas $\vec{\oplus}$ bubbles formed during or after decompression from $\infty$ the cavity of the diaphysis of the humerus or femur into the cancellous bone at the head and neck of the bone. Gas formation in the rigid confines of a bone will have a more devastating effect than in any other tissue. $^{3}$

In the haematopoietic bone marrow arteries divide $\stackrel{\mathbb{D}}{\stackrel{2}{2}}$ into smaller branches and then into arterial capillaries $\overrightarrow{\overrightarrow{0}}$ and sinuses with extraordinarily thin walls consisting $\frac{0}{3}$ of one layer of endothelial cells only. Gas bubbles would compress some of these flimsy vessels, and block blood flow to cause ischaemia. If this continued long enough, say for more than six to seven hours, ${ }^{4} \frac{\Phi}{3}$ then aseptic bone necrosis would be initiated. Replacement through creeping substitution would then begin eight to 10 days later, but only after three to six $\dot{\delta}$ months would changes become visible on the radiography. ${ }^{4}$ This is why it is impossible to relate the devel- 0 opment of osteonecrosis, as diagnosed on the radiograph, to a particular decompression.

Fat emboli and osmotic changes may also contribute to the development of aseptic osteonecrosis, $\mathcal{N}$ but the primary factor is gas under increased pressure, $N$ a consequence of the supersaturation of marrow fat. N

Despite the fact that a single exposure to com- $\omega$ pressed air may result in osteonecrosis, there is a correlation between the length of time spent in $\stackrel{0}{C}$ compressed air work and the frequency of osteonecrosis, but there is no statistical correlation between acute decompression sickness and aseptic osteonecrosis. These events are of a different nature. ${ }^{5}$

Arlet et al showed that the rise in pressure pro- $\frac{?}{\circ}$ 
voked by the injection of liquid into necrotic femoral heads did not return to normal in $80 \%$ of their cases, even after five minutes, a sign of insufficient or absent drainage in the necrotic femoral heads. ${ }^{5}$ Jones also stated that, "The flow of venous blood from an osteonecrotic lesion is invariably reduced or completely arrested and often greater pressure than usual is necessary in phlebography to inject the contrast medium. Frequently no venous drainage from the lesion is detected at all, and the contrast material pools within the cancellous bone. Venous stasis is associated with femoral head necrosis." 7

Earlier authors ${ }^{8}$ pointed out the frequency of lesions in the femoral heads "where end arteries are known to be frequently found." "Evidence that true end arteries occur in bone is equivocal and there appears to be free anastomosis between the vessels of the diaphysis, metaphysis, epiphysis, and the marrow. The femoral and humeral heads are relatively poorly supplied with arteries and this may play a part in the occurrence of structural failure in juxta-articular bone necrosis." 9

Interruption of blood flow may occur in the venous part of the circulation as well as in the arterial part: the ultimate effects would be the same, however.

The clinical consequences of an osteonecrotic lesion depend on its location.

(1) The so called juxta-articular lesions just beneath the articular surface of the bone are potentially disabling.

(2) Lesions of the head, neck, and shaft of a bone never cause disability. ${ }^{10}$

Structural failure occurs when the joint surfaces are no longer able to resist the stresses applied to them. ${ }^{4}$ Symptoms develop when the articular surface is deformed by collapse. ${ }^{11}$

\section{References}

${ }^{1}$ McCallum RI. Osteonecrosis in tunnel and caisson-workers. In: Beckman EL, Elliott DH, eds. Dysbarism-related osteonecrosis. Proceedings of a symposium on dysbaric osteonecrosis, Galveston, Galveston, Texas, 1972. Cincinnati: Department of Health, Education and Welfare, 1974:3-6. (NIOSH 75-153.)

${ }^{2}$ Kindwall EP. Milwaukee sewerage tunnel project. Cincinnati: Department of Health, Education and Welfare, 1974:41-6. (NIOSH 75-153.)

${ }^{3}$ Harvey CA. Decompression tables in relation to dysbaric osteonecrosis. Cincinnati: Department of Health, Education and Welfare, 1974:47-54. (NIOSH 75-153.)

${ }^{4}$ Miles JS. Discussion remark. Cincinnati: Department of Health, Education and Welfare, 1974:148 and 192. (NIOSH 75-153.)

${ }^{5}$ Rózsahegyi I. Die chronische Osteoarthropathie der Caissonarbeiter. Arch Gewerbepath 1956;14:483-9. (In German.)

${ }^{6}$ Arlet J, Ficat P, Lartigue G, Tran MA. Recherches cliniques sur la pression intra-osseuse dans la métaphyse et l'épiphyse femorales superieures chèz l'homme. Application au diagnostic des ischémies et nécroses. Rev Rhum 1972;39:717-23. (In French.)

7 Jones JP. Additional diagnostic techniques. Cincinnati: Department of Health, Education and Welfare, 1974:183-9. (NIOSH 75-153.)

${ }^{8}$ Kahlstrom SC, Burton CC, Phemister D. Aseptic necrosis of bone. I. Infarction of bones in caisson disease resulting in encapsulated and calcified areas in diaphyses and in arthritis deformans. Surg Gynecol Obstet 1939;68:129-46.

${ }^{9}$ McCallum RI. Dysbaric osteonecrosis: aseptic necrosis of bone. In: Bennett PB, Elliott DH, eds. The physiology and medicine of diving and compressed air work. London: Baillier Tindall, 1975: 504-21.

${ }^{10}$ Walder DN. Discussion remark. Cincinnati: Department of Health, Education and Welfare, 1974:160. (NIOSH 75-153.)

${ }^{11}$ Walder DN. Management and treatment. Cincinnati: Department of Health, Education and Welfare, 1974:196. (NIOSH 75-153.) 